\title{
Hyperoxia: A Stereologic Ultrastructural Examination of Its Influence on Cytoplasmic Components of the Pulmonary Granular Pneumocyte
}

\author{
Glorta D. Massaro and Donald Massaro \\ From the Pulmonary Division, Veterans Administration-George Washington \\ University Medical Center, Washington, D. C. 20422
}

\begin{abstract}
A B S T R A C T We used the technique of lineal analysis to study the influence of $48 \mathrm{~h}$ of hyperoxia on cytoplasmic organelles of pulmonary granular pneumocytes with particular reference to their lamellar bodies. We undertook this study because lamellar bodies are considered to be storage granules for pulmonary surfactant and because we had found that hyperoxia decreased $\left[{ }^{14} \mathrm{C}\right]$ leucine incorporation into protein of a surface-active lung fraction.

We found that for lamellar bodies the percent cytoplasmic volume was $12.8 \pm 1.5$ (mean $\pm S E M$ ) and $8.4 \pm$ 2.2 , the organelle area $\left(\mu \mathrm{m}^{2}\right)$ per organelle was $0.98 \pm$ 0.13 and $0.62 \pm 0.10$ and the organelle volume $\left(\mu \mathrm{m}^{3}\right)$ was $0.35 \pm 0.04$ and $0.18 \pm 0.01$, for air- and oxygenexposed rats, respectively, $(P=<0.05)$. The surface density of the lamellar body membrane was $7.05 \pm 0.47$ and 9.36 $\pm 0.96(P=<0.05)$ for air- and oxygen-exposed rats. There were no differences in lamellar body number per cytoplasmic area or per pneumocyte between air- and oxygen-exposed rats. There were no statistical differences in these parameters between mitochondria of air- or oxygen-exposed rats. The surface density of the rough endoplasmic reticulum was the same in both groups.

This study indicates that granular pneumocytes of rats exposed to hyperoxia have the same number of lamellar bodies as control rats but the lamellar bodies are smaller. This findings is consistent with the hypothesis that the hyperoxia-induced decrease in protein synthesis by lung represents at least in part a decreased synthesis of the secretory lipoprotein-pulmonary surfactant.
\end{abstract}

This work was presented in part at the 64th Annual Meeting of the American Society for Clinical Investigation, Atlantic City, N. J. May 1972.

Received for problication 3 August 1972 and in revised form 23 October 1972.

\section{INTRODUCTION}

It is currently thought that pulmonary surfactant lipoprotein is synthesized by granular pneumocytes and stored in their lamellar inclusion bodies before being secreted onto the alveolar surface $(1-6)$. We have shown that incorporation of $\left[{ }^{14} \mathrm{C}\right]$ leucine into protein of a surface active lung fraction, is decreased after in vivo exposure of rats to hyperoxia (7). These considerations make it reasonable to suspect that the decreased incorporation of $\left[{ }^{14} \mathrm{C}\right]$ leucine into protein of the surfaceactive lung fraction in rats exposed to hyperoxia might be reflected in alterations in the size, number, or both of these storage sites. We, therefore, undertook the present study which is a stereological examination of the influence of hyperoxia on the lamellar bodies of granular pneumocytes. We also examined the mitochondria and rough endoplasmic reticulum (RER) ${ }^{1}$ of these cells because of the possibility that hyperoxia might cause a general alteration in the size of cells or cytoplasmic organelles.

\section{METHODS}

Animals. We used Dublin Sprague-Dawley derived male rats (Flow Research Animals, Inc., Dublin, Va.). They were exposed to greater than $98 \% \mathrm{O}_{2}$ or air for $48 \mathrm{~h}$ as previously described (7).

Preparation of tissue. Rats were anesthetized by the intraperitoneal administration of sodium pentobarbital ( 30 $\mathrm{mg} / \mathrm{kg}$ ) and sacrificed by cutting the abdominal aorta. The right lung was excised and thin slices cut from the lower lobe. These were diced into tissue cubes of about $1 \mathrm{~mm}$ diameter and fixed for $1 \mathrm{~h}$ in cold cacodylate-buffered $1 \%$ osmium tetroxide. The tissue was dehydrated and embedded as previously described (4). The blocks were sectioned on a Porter-Blum ultramicrotome (Ivan Sorvall, Inc., Norwalk, Conn.) with a diamond knife. Sections with a silver interference color were picked up on 200 mesh copper grids.

${ }^{1}$ Abbreviation used in this paper: RER, rough endoplasmic reticulum. 


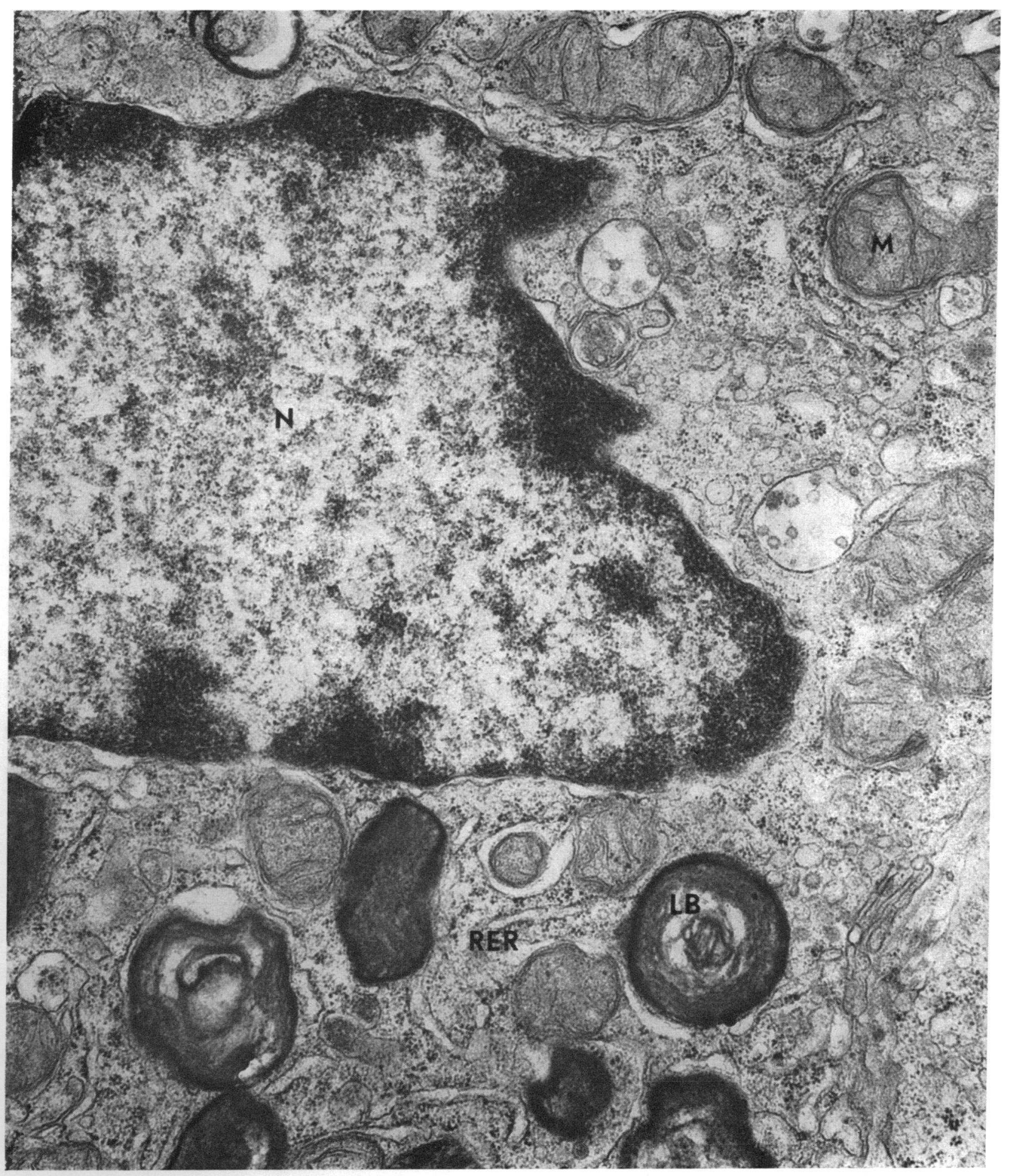

FIGURE 1 Electron micrograph of a pulmonary granular pneumocyte. This is a $25,000 \times$ magnification showing lamellar bodies $(L B)$ mitochondria $(M)$ and the rough endoplasmic reticulum $(R E R)$ which were measured; $N$, nucleus. Microvilli are seen in the right upper corner. 
TABLE I

Influence of Hyperoxia on Granular Pneumocyte Cytoplasmic Components

\begin{tabular}{lccc}
\hline & Air & $\mathrm{O}_{2,48 \mathrm{~h}}$ & $P$ \\
\hline Number of micrographs & $40(4)$ & $50(5)$ & \\
Total cytoplasmic area $\left(\mu \mathrm{m}^{2}\right)$ & 1933 & 2515 & \\
Cytoplasmic area per cell $\left(\mu \mathrm{m}^{2}\right)$ & $49.6 \pm 2.9$ & $50.3 \pm 1.5$ & $>0.5$ \\
\% cytoplasmic volume & & & \\
$\quad$ Mitochondria & $12.9 \pm 0.3$ & $15.7 \pm 1.3$ & $<0.1$ \\
$\quad$ Lamellar bodies & $12.8 \pm 1.5$ & $8.4 \pm 2.2$ & $<0.05$ \\
Organelle area $\left(\mu \mathrm{m}^{2}\right)$ per organelle & & & \\
$\quad$ Mitochondria & $0.89 \pm .06$ & $0.93 \pm 0.05$ & $<0.5$ \\
$\quad$ Lamellar bodies & $0.98 \pm 0.13$ & $0.62 \pm 0.10$ & $<0.05$ \\
Organelle count per $\mu \mathrm{m}^{2}$ cytoplasm & & & \\
$\quad$ Mitochondria & $0.15 \pm 0.01$ & $0.19 \pm 0.02$ & $<0.2$ \\
$\quad$ Lamellar bodies & $0.14 \pm 0.02$ & $0.14 \pm 0.02$ & $>0.5$ \\
\hline
\end{tabular}

Values in parentheses indicate number of rats. Mean \pm SEM are given.

They were stained with uranyl magnesium acetate and lead citrate (8) and examined with an AEI-6B electron microscope (AEI Scientific, White Plains, N. Y.).

Sampling procedures. The primary sample consisted of some 40 tissue cubes obtained from the right lower lobe of the lung of each rat. From these 40 tissue blocks five were chose at random to represent the secondary sample. Each of these blocks was sectioned at $1 \mu \mathrm{m}$ for light microscopy and at $600-900 \AA$ for electron microscope examination. Two electron micrographs of granular pneumocytes were taken from each of these five blocks. Thus, from each rat we used five blocks and made 10 micrographs. The micrographs of granular pneumocytes were taken randomly. Granular pneumocytes were identified as alveolar wall cells having lamellar inclusion bodies and microvilli (Fig. 1).

Stereologic procedures. Lineal analysis (9-11) of granular pneumocytes was made at a magnification of $\times 25,000$. Measurements were made on $8-\times-10$-inch enlarged prints of the micrographs. A square grid of white lines was superim- posed on each print by lengths of 7 mil wire placed on a frame at 1 inch intervals. Calibration checks were made on the electron microscope weekly and on the enlarging equipment before each use.

The micrographs from all rats (five exposed to oxygen and four air controls) were coded and were placed in random order by blindly drawing the coded number from a container and measurements were made in that order without knowledge of which group or animal the photographs represented. Lineal analysis and calculations of various parameters were performed as described in detail by others (9-11).

Statistical analysis. For each of the parameters measured or calculated from these measurements the values for individual animals were averaged per experimental group and the standard error of the group mean (SEM) calculated. The significance of differences between the oxygen-exposed and control rats were calculated by an unpaired $t$ test for groups of unequal size (12).

TABLE II

Surface Area of Lamellar Body and Mitochondrial Envelope and RER

\begin{tabular}{|c|c|c|c|}
\hline & $\begin{array}{l}\text { Air } \\
(4)\end{array}$ & $\begin{array}{c}\mathrm{O}_{2,48 \mathrm{~h}} \\
\quad(5)\end{array}$ & $P$ \\
\hline \multicolumn{4}{|l|}{ Total intersections counted } \\
\hline Lamellar body envelope & 814 & 878 & \\
\hline Mitochondrial envelope & 856 & 1412 & \\
\hline Rough endoplasmic reticulum & 584 & 728 & \\
\hline$\mu \mathrm{m}^{2}$ lamellar body envelope & \multirow{2}{*}{$7.05 \pm 0.47$} & \multirow{2}{*}{$9.36 \pm 0.96$} & \multirow{2}{*}{$<0.05$} \\
\hline$\mu \mathrm{m}^{3}$ lamellar body & & & \\
\hline$\mu \mathrm{m}^{2}$ mitochondrial envelope & \multirow[t]{2}{*}{$7.10 \pm 0.38$} & \multirow[t]{2}{*}{$7.72 \pm 0.39$} & \multirow[t]{2}{*}{$>0.2$} \\
\hline$\mu \mathrm{m}^{3}$ mitochondria & & & \\
\hline$\mu \mathrm{m}^{2}$ rough endoplasmic reticulum & \multirow[t]{2}{*}{$0.64 \pm 0.04$} & \multirow[t]{2}{*}{$0.59 \pm 0.04$} & \multirow[t]{2}{*}{0.4} \\
\hline$\mu \mathrm{m}^{3}$ cytoplasm & & & \\
\hline
\end{tabular}

Values in parentheses indicate number of animals. Mean \pm SEM are given. 
TABLE III

Dimensions of Lamellar Bodies and Mitochondria

\begin{tabular}{lccc}
\hline & $\begin{array}{c}\text { Air } \\
(4)\end{array}$ & $\begin{array}{c}\mathrm{O}_{2}, 48 \mathrm{~h} \\
(5)\end{array}$ & $P$ \\
\hline $\begin{array}{l}\text { Number or organelles counted } \\
\quad\end{array}$ & 248 & & \\
$\quad$ Lamellar bodies & 229 & 332 & \\
$\quad$ Mitochondria & & 434 & \\
Lamellar body dimensions & $0.62 \pm 0.07$ & $0.47 \pm 0.02$ & $<0.05$ \\
$\quad$ Average diameter $(\mu \mathrm{m})$ & $0.89 \pm 0.04$ & $0.77 \pm 0.06$ & $<0.2$ \\
$\quad$ Average length $(\mu \mathrm{m})$ & $0.35 \pm 0.04$ & $0.18 \pm 0.01$ & $<0.05$ \\
Average volume $\left(\mu \mathrm{m}^{3}\right)$ & & & \\
Mitochondrial dimensions & & & \\
$\quad$ Average diameter $(\mu)$ & $0.56 \pm 0.06$ & $0.52 \pm 0.03$ & $>0.5$ \\
$\quad$ Average length $(\mu)$ & $0.94 \pm 0.07$ & $1.03 \pm 0.07$ & $>0.5$ \\
$\quad$ Average volume $\left(\mu \mathrm{m}^{3}\right)$ & $0.31 \pm 0.05$ & $0.24 \pm 0.02$ & $<0.2$ \\
\hline
\end{tabular}

Values in parentheses indicate number of rats. Mean $\pm S E M$ are given.

\section{RESULTS}

Table I shows that hyperoxia did not alter the cytoplasmic area of granular pneumocytes. The percent of the cytoplasmic volume occupied by mitochondria is greater in the oxygen-exposed rats but the difference is not statistically significant. The number of mitochondria per cytoplasmic area is the same in both groups. The percent cytoplasmic volume occupied by lamellar bodies and the lamellar body area per lamellar body are significantly smaller in granular pneumocytes of oxygenexposed rats. The number of lamellar bodies are the same in both groups. These findings are in agreement with the measurements of the surface density of the lamellar body and mitochondrial envelopes (Table II). The surface density of the lamellar body envelope from rats exposed to hyperoxia is significantly greater than that of control rats. The surface density of the mitochondrial envelope and the membrane of the RER are the same in both groups.

Table III shows the dimensions of the lamellar bodies and mitochondria. The lamellar body volume of granular pneumocytes of oxygen-exposed rats is smaller than those of control rats. The mitochondrial dimensions are not significantly different in the two groups.

As in other studies oxygen exposure decreased the growth of the rats (Table IV).

\section{DISCUSSION}

A substantial amount of work in a variety of tissues has clearly established the morphological characteristics of cells which synthesize macromolecules for export (13). Ultrastructural studies of alveolar lining cells have shown that granular pneumocytes possess the morphological features characteristic of secretory cells; an abundant RER, a well-developed Golgi system and in- clusion bodies (lamellar bodies) (14). These structural indications of secretory activity are supported by biochemical evidence of intracellular protein transport and active secretion by lung tissue (15). Electron microscope autoradiography has localized at least some of this intracellular protein transport to be occurring from the RER to the lamellar bodies of the granular pneumocytes (4). This supports the concept that lamellar bodies are storage granules $(1,2)$. Askin and Kuhn (3), using radioactive palmitate, have shown that the grains become concentrated over the lamellar bodies as one would expect if these were storage granules.

More specifically, the lamellar bodies are thought to be storage sites for pulmonary surfactant. The evidence for this comes from two different approaches. First, the demonstration that a surface-active lung fraction is rich in these organelles (16). Secondly, and less direct, the large body of data showing a temporal relation in fetal life between the appearance of lamellar bodies, the rise in the lungs' content of dipalmitoyl lecithin, and the lungs' attainment of adult mechanical properties (17-21).

The present work has shown that the size of lamellar bodies of rats exposed to hyperoxia for $48 \mathrm{~h}$ are smaller

TABLE IV

Weight Data on Rats

\begin{tabular}{ccc}
\hline Weight & $\begin{array}{c}\text { Air } \\
(4)\end{array}$ & $\begin{array}{c}0_{2,48 \mathrm{~h}} \\
(5)\end{array}$ \\
\hline$g$ & & \\
Initial & $289.8 \pm 42.2$ & $283.8 \pm 40.0$ \\
Final & $307.0 \pm 28.3$ & $280.4 \pm 31.6$ \\
\hline
\end{tabular}

Values in parentheses indicate number of rats. Mean \pm SEM are given. 
than those of nonexposed rats. The failure to demonstrate comparable changes in the other cytoplasmic organelles examined (mitochondria and RER) and in the size of the granular pneumocytes themselves indicates the change in lamellar body size is not the result of a generalized oxygen-induced change in size due to alterations in membrane permeability and shifts in water. It does not exclude the theoretical possibility that oxygen selectively alters the permeability of lamellar body membranes causing the passage of water out of these structures and a decrease in their size.

Hyperoxia decreased the incorporation of $\left[{ }^{14} \mathrm{C}\right]$ leucine into protein in a surface-active lung fraction (7), to about the same extent as the decrease in lamellar body size. Thus, it would appear that in the face of a hyperoxia-induced decrease in synthesis of secretory protein the "packages" for export are smaller.

\section{ACKNOWLEDGMENTS}

Supported in part by the John A. Hartford Foundation, the American Thoracic Society and the Washington Heart Association and PHS grant 5-SO1-RR-5359-11.

We thank Dr. W. O. Dobbins III for advice during this study.

\section{REFERENCES}

1. Bensch, K., K. Schaefer, and M. E. Avery. 1964. Granular pneumocytes; electron microscopic evidence of exocrine function. Science (Wash. D. C.). 145: 1318.

2. Kuhn, C. 1968. Cytochemistry of pulmonary alveolar lining cells. Am. J. Pathol. 53: 809.

3. Askin, F. B., and C. Kuhn. 1971. The cellular origin of pulmonary surfactant. Lab. Invest. 25: 260.

4. Massaro, G. D., and D. Massaro. 1972. Granular pneumocytes. Electron microscopic radioautographic evidence of intracellular protein transport. Am. Rev. Respir. Dis. 105: 927.

5. Thomas, Jr., T., and R. A. Rhoades. 1970. Incorporation of palmitate- $1-{ }^{14} \mathrm{C}$ into lung tissue and "alveolar" lecithin. Am. J. Physiol. 219: 1535.

6. Young, S. L., and D. F. Tierney. 1972. Dipalmitoyl lecithin secretion and metabolism by the rat lung. Am. J. Physiol. 222 : 1539 .
7. Gacad, G., and D. Massaro. 1972. Hyperoxia: influence on lung mechanics and protein synthesis. J. Clin. Invest. $52: 559$.

8. Massaro, D., K. Kelleher, G. Massaro, and H. Yeager, Jr. 1970. Alveolar macrophages: depression of protein synthesis during phagocytosis. Am. J. Physiol. 218: 1533.

9. Loud, A. V. 1962. A method for the quantitative estimation of cytoplasmic structures. J. Cell Biol. 15: 481.

10. Loud, A. V., W. C. Barany, and B. A. Pack. 1965. Quantitative evaluation of cytoplasmic structures in electron micrographs. Lab. Invest. 14: 996.

11. Elias, H., A. Hennig, and D. E. Schwartz. 1971. Stereology: applications to biomedical research. Physiol. Rev. 51: 158 .

12. Snedecor, G. W., and W. C. Cochran. 1969. In Statistical Methods. The Iowa State University Press, Ames, Iowa. 91.

13. Schramm, M. 1967. Secretion of enzymes and other macromolecules. Annu. Rev. Biochem. 36: 307.

14. Sorokin, S. 1967. A morphologic and cytochemical study of the great alveolar cell. J. Histochem. Cytochem. 14: 884.

15. Massaro, D., H. Weiss, and M. R. Simon. 1970. Protein synthesis and secretion by lung. Am. Rev. Respir. Dis. 101: 198.

16. Frosolono, M. F., B. L. Charms, R. Pawlowski, and S. Slivka. 1970. Isolation, characterization and surface chemistry of a surface active fraction from dog lung. J. Lipid Res. 11: 439.

17. Brumley, G. W., Y. Chernick, W. A. Hodson, C. Normand, A. Fenner, and M. E. Avery. 1967. Correlations of mechanical stability, morphology, pulmonary surfactant, and phospholipid content in the developing lamb lung. J. Clin. Invest. 46: 863.

18. Buckingham, S., and M. E. Avery. 1962. Time of appearance of lung surfactant in the fetal mouse. Nature (London.). $193: 688$.

19. Kikkawa, Y., E. K. Motoyama, and C. D. Cook. 1965. The ultrastructure of the lungs of lambs. Am. J. Pathol. $47: 877$.

20. Kotas, R. V., and M. E. Avery. 1971. Accelerated appearance of pulmonary surfactant in the fetal rabbit. J. Appl. Physiol. 30: 358 .

21. Wang, N. S., R. V. Kotas, M. E. Avery, and W. M. Thurlbeck. 1971. Accelerated appearance of osmiophilic bodies in the fetal lungs following steroid injection. $J$. Appl. Physiol. 30: 362. 